1. FCPS

Associate Professor

Department of Urology and Renal

Transplantation

Bahawal Victoria Hospital/

Quaid-e-Azam Medical College,

Bahawalpur.

2. MS Urology

Assistant Professor

Department of Urology

Shahida Islam Medical College,

Lodhran.

3. FCPS

Senior Registrar

Department of Radiology

Bahawal Victoria Hospital/

Quaid-e-Azam Medical College,

Bahawalpur.

4. FCPS

Senior Registrar

Department of Urology and Renal

Transplantation

Bahawal Victoria Hospital/

Quaid-e-Azam Medical College,

Bahawalpur.

5. FCPS

Head

Department of Urology and Renal

Transplantation

Bahawal Victoria Hospital/

Quaid-e-Azam Medical College,

Bahawalpur.

Correspondence Address:

Dr. Mudassar Saeed Pansota

House \# 95/A, Muhammadia Colony,

Noor Mahal Road, Bahawalpur.

netygeulis749@hotmail.com

Article received on:

13/06/2018

Accepted for publication:

18/04/2019

Received after proof reading:

$30 / 09 / 2019$

\section{POSITIVE PREDICTIVE VALUE (PPV) OF COMPUTED TOMOGRAPHY IN DIAGNOSING WILMS' TUMOR USING HISTOPATHOLOGY AS GOLD STANDARD.}

\author{
Mumtaz Rasool', Mudassar Saeed Pansota ${ }^{2}$, Fariha Mumtaz ${ }^{3}$, Muhammad Shahzad Saleem ${ }^{4}$, \\ Shafqat Ali Tabassum ${ }^{5}$
}

ABSTRACT: CT can also accurately identify vascular invasion that will impact surgical approach along with identification of the preoperative parameters associated with increased risk of intraoperative Wilms' tumor spill. Objectives: To determine positive predictive value of CT scan in diagnosing wilm's tumour, taking histopathology as gold standard. Study Design: Descriptive, cross sectional study. Setting: Department of Urology \& Renal Transplantation Centre, Bahawal Vitoria Hospital, Bahawalpur. Period: From July 2017 to June 2018. Materials \& Methods: A total of 81 patients with suspected wilm's tumour on ultrasonography of age 1-12 years of either gender were included. Patients with recurrent tumour and undergoing preop chemotherapy were excluded. All the patients were then underwent CT scan and looked for presence or absence of wilm's tumour. The results were compared with histopathology. Results: Mean age was $5.23 \pm 3.28$ years. Majority of the patients $56(69.14 \%)$ were between 1 to 6 years of age. Out of these 81 patients, 61 (75.31\%) were female and $20(24.69 \%)$ were males with female to male ratio of 2.9:1. CT scan supported the diagnosis of wilm's tumour in all 46 patients. Histopathology confirmed wilm's tumour in 41 (true positive) cases where as 05 (False Positive) had no wilm's tumour on histopathology. Positive predictive value of CT scan in diagnosing wilm's tumour, taking histopathology as gold standard was $89.13 \%$. Conclusion: This study concluded that positive predictive value of CT scan in diagnosing wilm's tumour is quite high.

Key words: $\quad$ Computed Tomography, False Positive, Histopathology, Imaging, Positive Predictive Value, True Positive, Wilm's Tumour.

Article Citation: Rasool M, Pantosa MS, Mumtaz F, Saleem MS, Tabassum SA. Positive predictive value (PPV) of computed tomography in diagnosing wilms' tumor taking histopathology as gold standard. Professional Med J 2019; 26(10):1755-1759. DOI: 10.29309/TPMJ/2019.26.10.4136

\section{INTRODUCTION}

The Wilms' tumor or nephroblastoma is the most common renal neoplasm in pediatrics age group, accounting for $87 \%$ of all renal masses. ${ }^{1}$ The tumor occurs in both hereditary and sporadic forms, and approximately $6 \%$ are bilateral. Most are unicentric and arise from the kidney. Asymptomatic abdominal mass is the most common clinical presentation. Almost 25\% patients have shown secondary hypertension which is due to increased renin levels. Ultrasonography is the commonly performed initial investigation which has shown a smooth, uniform echogenic well defined mass. ${ }^{2}$

The average age at presentation of wilms' tumor is $42-47$ months for children with unilateral tumor and 30-33 months for those with bilateral tumor.
However the peak incidence is between 3 and 4 years of age for unilateral tumors while bilateral tumors $\left(4-13 \%\right.$ cases) present at a younger age. ${ }^{3}$

Non-Wilms' tumors may represent a significant proportion of renal tumors in children, especially in children aged less than 6 months or greater than 12 years. ${ }^{4}$

Computerized tomography helps in assessing the origin of the tumor; bilateral renal involvement; lymph node involvement; and invasion into the renal vessels, Inferior vena cava or right atrium. ${ }^{5}$

The crescent sign, the embedded kidney sign, the beak sign and the renal arteries feeding sign are the specific findings of computed tomography 
which help in distinguishing renal tumours from non-renal origin tumors. ${ }^{6}$

CT can also accurately identify vascular invasion that will impact surgical approach along with identification of the preoperative parameters associated with increased risk of intraoperative Wilms' tumor spill. ${ }^{7}$

Histological diagnosis remains indispensable however the radiology together with clinical and epidemiological data enables the proper diagnostic work-up of pediatric renal tumors. ${ }^{8}$

By defining a radiological cutoff size for suspicious lymph nodes, preoperative computerized tomography for staging lymph nodes in Wilms' tumor demonstrates potential clinical usefulness for therapy. ${ }^{9}$

On searching the literature, I have found no local study in this aspect, so I had decided to conduct a study to determine the positive predictive value of CT scan in diagnosing wilm's tumour, taking histopathology as gold standard. The results of this study will not only provide the local stats but will also if PPV of CT will be found high, then this non-invasive imaging modality should be used routinely in our general practice for proper diagnosis and pre-operative management plans accordingly in order to reduce the morbidity and mortality of our community.

\section{MATERIALS AND METHODS}

This descriptive, cross sectional study was done on 81 patients with suspected wilm's tumour on ultrasonography (isoechoic, hypoechoic, or hyperechoic relative to the remainder of the renal parenchyma) and age between 1-12 years of both genders who were presented at department of Urology \& Renal Transplantation Centre, Bahawal Vitoria Hospital, Bahawalpur were selected for the study. Patients undergoing pre-op chemotherapy and recurrent tumour were excluded from the study.

After taking informed consent and relevant history, all the subjects were undergone pre-contrast and contrast-enhanced CT scanning of the KUB. Standard CT technique for evaluation of patients with Wilms' Tumor included post-contrast axial images from top of kidneys to symphysis pubis. Contrast was given by calculation with patients age and weight, and contrast-enhanced imaging is done during the nephrographic phase (by using a scanning delay of 90 seconds). Section collimation of $5 \mathrm{~mm}$ is routinely used and thinner sections can be reconstructed with sagittal and coronal reformat as required.

CT scan findings were interpreted by the consultant Radiologist (at least 5 years of postfellowship experience) as presence or absence of wilm's tumour. All patients were then undergone surgery in the department by the consultant urologist and the specimen of the diseased kidney after nephrectomy was sent to the institutional pathology laboratory for histopathology. CT scan findings were compared with histopathology report.

Data was stored and analyzed by using computer software SPSS version 20. The quantitative variables were presented by mean and standard deviations. The qualitative variables like were presented by frequency and percentage. 2x2 contingency table was used to calculate the positive predictive value of CT scan in diagnosing wilm's tumour.

\section{RESULTS}

Mean age was $5.23 \pm 3.28$ years. Majority of the patients $56(69.14 \%)$ were between 1 to 6 years of age. Out of these 81 patients, 61 (75.31\%) were female and 20 (24.69\%) were males with female to male ratio of $2.9: 1$. Mean duration of disease was $4.75 \pm 3.38$ months. Mean BMI was $28.01 \pm$ $4.43 \mathrm{~kg} / \mathrm{m} 2$.

CT scan supported the diagnosis of wilm's tumour in all 46 patients. Histopathology confirmed wilm's tumour in 41 (true positive) cases where as 05 (False Positive) had no wilm's tumour on histopathology (Table-I). Positive predictive value of CT scan in diagnosing wilm's tumour, taking histopathology as gold standard was $89.13 \%$. 


\begin{tabular}{|c|c|c|c|}
\hline & $\begin{array}{l}\text { Positive Result on } \\
\text { Histopathology }\end{array}$ & $\begin{array}{l}\text { Negative Result on } \\
\text { Histopathology }\end{array}$ & P-Value \\
\hline Positive results on CT scan & $41(\mathrm{TP})^{\star}$ & $05(\mathrm{FP}) * * *$ & 0.0001 \\
\hline
\end{tabular}

Table-I. Positive predictive value of CT scan in diagnosing wilm's tumour, taking histopathology as gold standard $(n=81)$.

${ }^{*}$-TP $=$ True positive ${ }^{*}$-FP $=$ False positive

True Positive

Positive Predictive $=\quad x 100=\mathbf{8 9 . 1 3 \%}$

value $\quad$ True Positive + False Positive

\section{DISCUSSION}

Wilms tumor is the most common cause of abdominal tumors in children in Sub-Saharan Africa, ${ }^{10-14}$ accounting for about $6 \%$ of all pediatric malignancies in the United States. ${ }^{12,13}$ Other less common causes of abdominal childhood tumor include neuroblastoma, multicystic kidney disease, hydronephrosis and polycystic kidneys. Its incidence is 1 in 10,000 children, representing about 650 new cases annually in the United States. ${ }^{12,13}$ It tends to occur between ages 1 and 3 years and $90 \%$ of new cases are diagnosed before 7 years. Occasionally, Wilms' tumor has been seen in teenagers and adults.

It is a known fact that modern imaging techniques are valuable for diagnosis of Wilms' tumor before confirmation by histology..$^{15}$ Imaging and various radiographic features help to make a distinction of the various renal masses and thus make a precise preoperative diagnosis. Recent advances in high end on imaging techniques have shown that it is possible to diagnose this disease entity in its early stage in developed society, but in resource limited countries such as ours, patients present late, making its management challenging. In such cases, the tumor may be too large and may have metastasized before presentation. ${ }^{16}$ Ultrasound with Color Doppler, Computed tomography (CT) scan and magnetic resonance imaging (MRI) are all modern imaging techniques that have proved useful for diagnosis. However, the cross sectional imaging like CT scan and
MRI have been shown to be superior to ultrasonography. ${ }^{17} \mathrm{CT}$ has been found to have accuracy of $82 \%$ and capable of an explicit report in $89 \%$ of all cases. ${ }^{18}$

Age range in my study was from 1-12 years with mean age of $5.23 \pm 3.28$ years. Majority of the patients $56(69.14 \%)$ were between 1 to 6 years of age. Out of these 81 patients, $61(75.31 \%)$ were female and 20 (24.69\%) were males with female to male ratio of $2.9: 1$. CT scan supported the diagnosis of wilm's tumour in all 46 patients. Histopathology confirmed wilm's tumour in 41 (true positive) cases where as 05 (False Positive) had no wilm's tumour on histopathology. Positive predictive value of CT scan in diagnosing wilm's tumour, taking histopathology as gold standard was $89.13 \%$. In one study the CT reports have given true diagnosis in $89 \%$ of cases with a diagnostic accuracy of $82 \%$ while the sensitivity, specificity, PPV, and NPV for computed tomography (CT) determining a diagnosis of wilm's tumour were $92 \%, 55 \%$, $84 \%$, and $73 \%$ respectively. ${ }^{19}$

CT is currently the technique of choice in the diagnosis and staging of renal masses in children, and is particularly relevant in recognition of size and site of lesion and densitometric patterns. ${ }^{11}$ It also provides an excellent visualization of contiguous structures like vessels and lymph nodes. ${ }^{11}$ A study comparing the CT and MRI in pediatric renal tumours has shown the sensitivity of computed tomography and magnetic resonance imaging for detecting capsular penetration as $68.6 \%$ and $62.9 \%$, respectively $(P=0.73)$, while specificity as $86.5 \%$ and $83.8 \%(P=1.0)$. The sensitivity of computed tomography and magnetic resonance imaging for detecting lymph node metastasis as $76.5 \%$ and $52.9 \%$ 
$(\mathrm{P}=0.22)$, and specificity was $90.4 \%$ and 92.3\% $(P=1.0) .{ }^{20}$ Poor correlation between computed tomography and histopathology was found by Gow et al. ${ }^{21}$ The author has shown correct staging in $38 \%$ patients. In the above study, staging with $\mathrm{CT}$ was correct in 10 out of 26 patients (38\%). ${ }^{21}$

\section{CONCLUSION}

This study concluded that positive predictive value of CT scan in diagnosing wilm's tumour is quite high, and has not only dramatically improved our ability of diagnosing wilm's tumour pre-operatively but also helps the surgeons for proper decision making. So, we recommend that computed tomography (CT) scan should be done routinely in all suspected cases of wilm's tumour for accurate assessment pre-operatively and opting proper surgical approach.

\section{Copyright@ 18 Apr, 2019.}

\section{REFERENCES}

1. Wu YH, Song B, Gong QY, Wu B, Chen WX, Liu RB, et al. Retroperitoneal neoplasms within the perirenal space in infants and children: Differentiation of renal and non-renal origin in enhanced CT images. EJR. 2010; 75(3):279-86.

2. Dahnert WF. Radiology review manual. 6th ed. Lippincott Williams \& Wilkins; 2007. 992-3.

3. Barber TD, Derinkuyu BE, Wickiser J, Joglar J, Koral K, Baker LA. Wilms tumor: Preoperative risk factors identified for Intraoperative tumor Spill J Urol. 2011; 185(4):1414-18.

4. Geller E, Kochan PS. Renal neoplasms of childhood. Radiol Clin North Am. 2011; 49(4):689-709.

5. Khanna G, Rosen N, Anderson JR, Ehrlich PF, Dome JS, Gow KW, et al. Evaluation of diagnostic performance of CT for detection of tumor thrombus in children with Wilms tumor: A report from the Children's Oncology Group. Pediatr Blood Cancer. 2012; 58(4):551-5.

6. Lubahn JD, Cost NG, Kwon J, Powell JA, Yang M, Granberg CF, et al. Correlation between preoperative staging and computerized tomography and pathological findings after nodal sampling in children with wilms tumor. J Urol. 2012; 188(4):1500-505.

7. La Parra Casado C, MuroVelilla D, Molina FR, Sangüesa NC. Radiologic findings in non-Wilms' renal tumors in children. Radiol. 2008; 50(3):215-24.
8. Fufezan O, Asavoaie C, Blag C, Popa G. The role of ultrasonography for diagnosis the renal masses in children. Pictorial essay. Med Ultrason. 2011; 13(1):5971.

9. Wu YH, Song B, Gong QY, Wu B, Chen WX, Liu RB, Wu B, Li ZL. Renal and non- renal tumors within the perirenal space in infants and children: Multidetector row CT characteristics. Sichuan Da Xue Xue Bao Yi Xue Ban. 2010; 41(2):288-91.

10. Ekenze SO, Heij HA, Youngson GG. Paeditric surgery: A comprehensive text for Africa. Seattle, WA: Global HELP Organisation; 2011. Kidney tumours; pp. 610-3.

11. Miele V, Galluzzo M, Bellussi A, Valenti M. Spiral computerized tomography in the study of renal neoplasms in children. Radiol Med. 1998; 95:486-92.

12. Kim S, Chung DH. Pediatric solid malignancies: Neuroblastoma and wilms tumor. Surg Clin North Am. 2006; 86:469-87.

13. Lowe RE, Cohen MD. Computed tomographic evaluation of Wilm's tumour and neuroblastoma. Radiograph. 1984; 4:915-28.

14. Olukayode AA, Richard IO, Rachael AA, Babajide $\mathrm{OB}$, Ireti OF, Gbolahan OA. Pattern of computed tomography scan findings in children with Wilms' tumor in a tertiary hospital in Lagos, Nigeria. Indian journal of medical and paediatric oncology: 2014 Jan;35(1):31.

15. Riccabona $M$. Imaging of renal tumours in infancy and childhood. Eur Radiol. 2003; 13(Suppl 4):L116-29.

16. Osuoji RI, Williams OM, Ajai OT, Idika OC, Abolarinwa AA, Bankole MA. Wilms' tumour: Experience in a developing tertiary centre in Nigeria. East Cent Afr $\mathrm{J}$ Surg. 2011; 16:52-8.

17. Rohrschneider WK, Weirich A, Rieden K, Darge K, Tröger J, Graf N. US, CT and MR imaging characteristics of nephroblastomatosis. Pediatr Radiol. 1998; 28:43543.

18. Miniati D, Gay AN, Parks KV, Naik-Mathuria BJ, Hicks J, Nuchtern JG, et al. Imaging accuracy and incidence of Wilms' and non-Wilms' renal tumors in children. $J$ Pediatr Surg. 2008; 43:1301-7.

19. Miniati D, Gay AN, Parks KV, Naik-Mathuria BJ, Hicks J, Nuchtern JG, et al. Imaging accuracy and incidence of Wilms' and non-Wilms' renal tumors in children. $J$ Pediatr Surg. 2008; 43(7):1301-7. 
20. Servaes S, Khanna G. Comparison of diagnostic performance of CT and MRI for abdominal staging of pediatric renal tumors: A report from the children's oncology group. Pediatr Radiol. 2015; 45(2):166-172.
21 Gow KW, Roberts IF, Jamieson DH. Local staging of Wilms' tumor - computerized tomography correlation with histological findings. J Pediatr Surg. 2000; 35:677-9.

\section{AUTHORSHIP AND CONTRIBUTION DECLARATION}

\begin{tabular}{|c|c|c|c|}
\hline Sr. \# & Author-s Full Name & Contribution to the paper & Author's Signature \\
\hline 1 & Mumtaz Rasool & $\begin{array}{l}\text { Conception adn Design, acquisition } \\
\text { of data, Analysis and interpretation } \\
\text { of data, Drafting and critical revision, } \\
\text { Final approval of the version to be } \\
\text { published. }\end{array}$ & \\
\hline 2 & Mudassar Saeed Pansota & $\begin{array}{l}\text { Conception adn Design, acquisition } \\
\text { of data, Analysis and interpretation } \\
\text { of data, Drafting and critical revision, } \\
\text { Final approval of the version to be } \\
\text { published. }\end{array}$ & \\
\hline 3 & Fariha Mumtaz & $\begin{array}{l}\text { Conception and Design, Acquisition } \\
\text { of data, analysis and interpretation of } \\
\text { data. }\end{array}$ & \\
\hline 4 & M. Shahzad Saleem & $\begin{array}{l}\text { Acquisition of data, Drafting and final } \\
\text { approval of the manuscript. }\end{array}$ & \\
\hline 5 & Shafqat Ali Tabassum & $\begin{array}{l}\text { Conception adn Design, acquisition } \\
\text { of data, Analysis and interpretation } \\
\text { of data, Drafting and critical revision, } \\
\text { Final approval of the version to be } \\
\text { published. }\end{array}$ & Shateuts \\
\hline
\end{tabular}

